\title{
Couples HIV counselling and couple relationships in India, Georgia and the Dominican Republic
}

\author{
Thierry Tiendrebeogo ${ }^{1,2^{*}} \mathbb{D}$, Melanie Plazy ${ }^{1,2}$, Shrinivas Darak ${ }^{3}$, Marija Miric ${ }^{4}$, Eddy Perez-Then $^{4}$, Maia Butsashvili $^{5}$,
} Patrice Tchendjou ${ }^{6,7}$, François Dabis ${ }^{1,2}$ and Joanna Orne-Gliemann ${ }^{1,2}$

\begin{abstract}
Background: Couples HIV counseling and testing is essential for combination HIV prevention, but its uptake remains very low. We aimed to evaluate factors associated with couples HIV counseling uptake in India, Georgia and the Dominican Republic, as part of the ANRS 12127 Prenahtest intervention trial.

Methods: Pregnant women $\geq 15$ years, attending their first antenatal care (ANC) session between March and September 2009, self-reporting a stable partner, and having received couple-oriented post-test HIV counseling (trial intervention) were included. Individuals and couple characteristics associated with the acceptability of couples HIV counseling were assessed using multivariable logistic regression for each study site.

Results: Among 711 women included (232, 240 and 239 in the Dominican Republic, Georgia and India, respectively), the uptake of couples HIV counseling was $9.1 \%$ in the Dominican Republic, 13.8\% in Georgia and 36.8\% in India. The uptake of couples HIV counseling was associated with women having been accompanied by their partner to ANC, and never having used a condom with their partner in the Dominican Republic; with women having been accompanied by their partner to ANC in India; with women having a higher educational level than their partner and having ever discussed HIV with their partner in Georgia.

Conclusion: Couple HIV counseling uptake was overall low. Strategies adapted to local socio-cultural contexts, aiming at improving women's education level, or tackling gender norms to facilitate the presence of men in reproductive health services, should be considered.
\end{abstract}

Trial registration: ClinicalTrials.gov Identifier: NCT01494961. Registered December 15, 2011. (Retrospectively registered).

Keywords: HIV, Couples HIV counseling, Antenatal care, Male partner

\section{Background}

Worldwide, an estimated 2.1 million people became newly infected with HIV infection in 2015 [1]. A very large part of these new infections occurred within heterosexual and serodiscordant stable couple relationships [2], as evidenced by the abundant literature from subSaharan Africa [3-6]. Several Asian countries have also reported high levels of intimate partner transmission of

\footnotetext{
* Correspondence: kiswend-sida-thierry.tiendrebeogo@u-bordeaux.fr 'INSERM UMR 1219 - Bordeaux Population Health Research Center, Bordeaux, France

${ }^{2}$ Universite Bordeaux, Institut de Santé Publique, d'Epidémiologie et de Développement (ISPED), 146 rue Leo Saignat, 33076 Bordeaux cedex, France Full list of author information is available at the end of the article
}

HIV [7], with women living with HIV being infected by their married partner who engaged in unsafe behaviors, prior or after marriage [8]. Preventing HIV transmission among serodiscordant couples thus remains a key target in the worldwide fight against HIV.

Significant new advances have taken place in the past years in the field of HIV prevention research, mainly in the field of biomedical interventions for serodiscordant couples. The HPTN052 trial showed that when an HIVinfected person is on antiretroviral (ARV) treatment (ART) with good adherence, his/her risk of HIV transmission to his/her uninfected partner is significantly decreased [9]. Within the PARTNER Pre-exposure Prophylaxis (PreP) study, when the HIV-negative partner 
used ARV drugs as prophylaxis, his/her risk of HIV acquisition from the HIV-infected partner was significantly reduced [10]. This evidence contributed to the revision of the World Health Organization guidelines in September 2015, which recommend initiation of ART to all HIV-infected people regardless of their immunological status, as well as ARVs as prophylaxis for serodiscordant couples [11].

Implementing biomedical interventions aiming at preventing HIV acquisition and transmission within couples requires a first critical step, i.e. HIV status awareness within couples. Couple members who get tested together and mutually disclose their HIV status are more likely to adopt HIV prevention behaviors, both in HIV concordant or discordant relationships [12-17]. Further, women who receive prenatal HIV counseling along with the partner are more likely to adhere to prevention of mother-to-child transmission (PMTCT) interventions when they test HIVpositive than those who are counseled individually [18].

Couples HIV counseling and testing has been encouraged by international agencies for many years [19], but efforts have mainly been restricted to the context of generalized HIV epidemics in sub-Saharan Africa [20, 21]. Extensive research has been conducted on couples HIV counseling in Rwanda and Zambia, including on promotion strategies $[22,23]$ and on the profile of couples accepting such services - in Zambia, having been previously tested for HIV and cohabiting were among the main factors associated with couples HIV counseling uptake [23]. In Zambia, couples HIV counseling was shown to be associated with sustained reductions in selfreported unprotected sex [24]. High rates of couples HIV counseling were recently reported at national level in Rwanda, preventing an estimated $>70 \%$ of incident HIV infections [25]. In most countries however, the proportion of couples who test together in the context of pregnancy is less than 20\% [26], and the provision of couple HIV counseling and testing services is low [27].

There is little data on the uptake of couples HIV counseling and testing in low to medium HIV prevalence countries and outside sub-Saharan Africa. And yet in such settings, low coverage of HIV testing clearly represents missed opportunities for preventing primary acquisition of HIV within couples. Further, the role of different types of couple relationships and gender norms, and of the local social and epidemiological contexts, on the acceptability of couple approaches to HIV prevention is poorly understood.

This paper aims to describe the uptake of and factors associated with couples HIV counseling in low HIV prevalence settings.

\section{Methods}

\section{Study setting: The 12,127 Prenahtest trial}

We conducted this analysis using the data collected in the ANRS 12127 Prenahtest study, a multicenter randomized controlled trial carried out between 2009 and 2011 in four urban health facilities located in Yaoundé (Cameroon), Santo Domingo (The Dominican Republic), Tbilisi (Georgia) and Pune (Maharashtra province, India). In 2014, HIV prevalence among adults aged 15-49 was estimated at $0.3 \%$ in Georgia, $0.4 \%$ in Maharashtra province, $0.8 \%$ in the Dominican Republic in 2014 and $4.8 \%$ in Cameroon [28].

Trial methods were described previously [29]. In summary, the trial was designed to evaluate the acceptability, feasibility and impact of an innovative prenatal counseling intervention offered to pregnant women, named Couple-Oriented post-test HIV Counseling (COC). The main study outcomes were the frequency of men's HIV testing, couples HIV counseling and couples HIV testing, as well as sexual, reproductive, and HIV prevention behaviors. Pregnant women were recruited during antenatal care (ANC). The trial baseline criteria were acceptance of trial participation, being aged 15 years or older, attending their first ANC visit in the four study centers between March and September 2009, no previous HIV test during their current pregnancy, and self-reporting having a stable partner. Women who were unable to provide consent due to mental illness at baseline, or those whose partner was absent for more than six months a year or whose partner had been tested for HIV during the current pregnancy were not eligible. Enrolled women were randomized to receive either Standard post-test HIV Counseling (SC arm) or the COC intervention (COC arm) [25]. Specifically trained HIV counselors delivered the COC intervention. COC sessions included role-play to develop women's communication skills, especially to discuss HIV and sexual issues with their partner. Women were also encouraged to invite their partner for HIV testing [29] and couples HIV counseling. All women responded to three face-to-face questionnaires: at baseline, before HIV testing (T0), within two to eight weeks after post-test HIV counseling (T1) and six months post-partum (T2).

\section{Study population}

This analysis is restricted to the three low HIV prevalence countries (The Dominican Republic, Georgia and India) and to women randomized in the $\mathrm{COC}$ group. We excluded women who had missing data for study variables.

\section{Variables of interest}

Our outcome of interest was the uptake of couples HIV counseling at the end of the trial, defined as pre-test HIV counseling received together by both partners (even if the couple did not receive couples HIV testing or couples post-test HIV counseling). It was measured from two main sources: i/women self-reports within 
the questionnaires administered at T1 and T2 and ii/ a trial impact form in which all events of interest for the trial (partner HIV testing and couples HIV counseling in particular) were notified by local trial coordinators. We assumed that women not seen at T1 or $\mathrm{T} 2$ and without any information in the trial impact form did not receive couples HIV counseling during the study period.

Individual and couple-related characteristics were included in our analysis. Individual characteristics included age and educational level of the pregnant woman, women's HIV testing history and reported partner's HIV testing history. Couple-related characteristics included age and educational difference between the two partners, remunerated activity in the couple, cohabitation, duration of the relationship, report to be accompanied by partner to ANC, perception of partner support for pregnancy, report of emotional, verbal abuse or physical abuse at least once in the last month, and report of past discussion within the couple about HIV and condom use.

\section{Statistical analysis}

We described the uptake of couples HIV counseling at the end of the study for each study site/country. Individual and couple characteristics at baseline were described in terms of numbers and frequencies. Unadjusted (univariable) and multivariable logistic regression models for each study site were used to assess the association between the uptake of couples HIV counseling and the individual and couple-related characteristics. We used a likelihood ratio test (LRT) to screen for variables to be included in the adjusted (multivariable) analyses. Factors that were significant at $P<0.25$ in unadjusted analyses and woman age as confounder were included in the multivariable model. Final models were retained using a backward elimination approach and after checking for confounding factors. Analyses were carried out using SAS version 9.3.

\section{Ethics statement}

The Prenahtest study was approved by Comité de Ética Indepediente, Fundación Dominicana de Infectología (9 April 2007, Dominican Republic), IRB 00006752 of Maternal and Child Care Union (13 November 2008, Georgia), Independent Ethics Committee for Prayas Health Group (27 March 2007, India). Participants were assigned identification numbers and all questionnaires and process forms were labeled with matching numbers to maintain confidentiality.

\section{Results}

Description of the study population

Overall, 1459 pregnant women were recruited and randomized in the three Prenahtest trial study sites, and
1445 of them responded to the baseline questionnaire. We excluded 723 women randomized to the SC groups and 11 with missing data. A total of 711 pregnant women were included in the analysis, among which 232 in the Dominican Republic, 240 in Georgia and 239 in India (Fig. 1).

Individual and couple characteristics at baseline are described in Table 1.

Dominican and Indian women were aged 21 years in median (interquartile range $(\mathrm{IQR})=[19-27]$ and $\mathrm{IQR}=$ [20-23], respectively) and most of them had completed less than 13 years of education $(91.5 \%$ and $87.5 \%$, respectively). Georgian women were aged 25 years in median $(\mathrm{IQR}=[22-30])$ and most of them $(70.8 \%)$ had completed at least 13 years of education.

In Georgia, $80 \%$ of women reported being in a married relationship. All women enrolled in India were married. In the Dominican Republic, $>84 \%$ reported living in free union (i.e. living with a partner without legal or religious recognition). Women often lived with both their partner and his family members in Georgia (45\%) and India (52\%), while in Dominican Republic women were more likely to live with their partner only (i.e. as a nuclear family) (76.7\%).

In all three sites, less than one third of pregnant women were employed at the time of enrolment and up to $20 \%$ of both partners were not working in Georgia. Few women had a higher educational level than their partner (respectively 24\%, 29\% and 39\% of women in Georgia, India and the Dominican Republic).

In all three countries, women had occasionally been accompanied by their partner to their first ANC visit: $44 \%$ in India, 38\% in Georgia and 28\% in the Dominican Republic. Approximately two thirds of women in the Dominican Republic and India perceived their partner as very supportive of their pregnancy. $48.3 \%$ of women in the Dominican Republic reported experiencing emotional or verbal abuse from their partner at least once in the last month prior enrolment. This proportion was lower in Georgia (25.8\%) and India (19.7\%). Physical abuse by the partner in the last month was reported by $16.3 \%$ of women in India, 10.3\% in the Dominican Republic and $1.7 \%$ in Georgia. Frequent alcohol consumption by their partner was reported by $3.8 \%$ of women in the Dominican Republic, 6.9\% in Georgia and 6.6\% in India.

Previous HIV testing was reported by $37.9 \%$ of women in Georgia, $33.9 \%$ in India, and $27.8 \%$ in the Dominican Republic. HIV testing history among men, as reported by women, was below $10 \%$ in Georgia and India, and 41.4\% in Dominican Republic.

At enrolment, $58.3 \%$ of women in Georgia, $54.1 \%$ in India and $38.4 \%$ in the Dominican Republic reported never having discussed about HIV with their partner; $43.1 \%$ of women in the Dominican Republic, $30.0 \%$ in Georgia and $26.8 \%$ in India reported ever having used condoms for HIV prevention with their partner. 


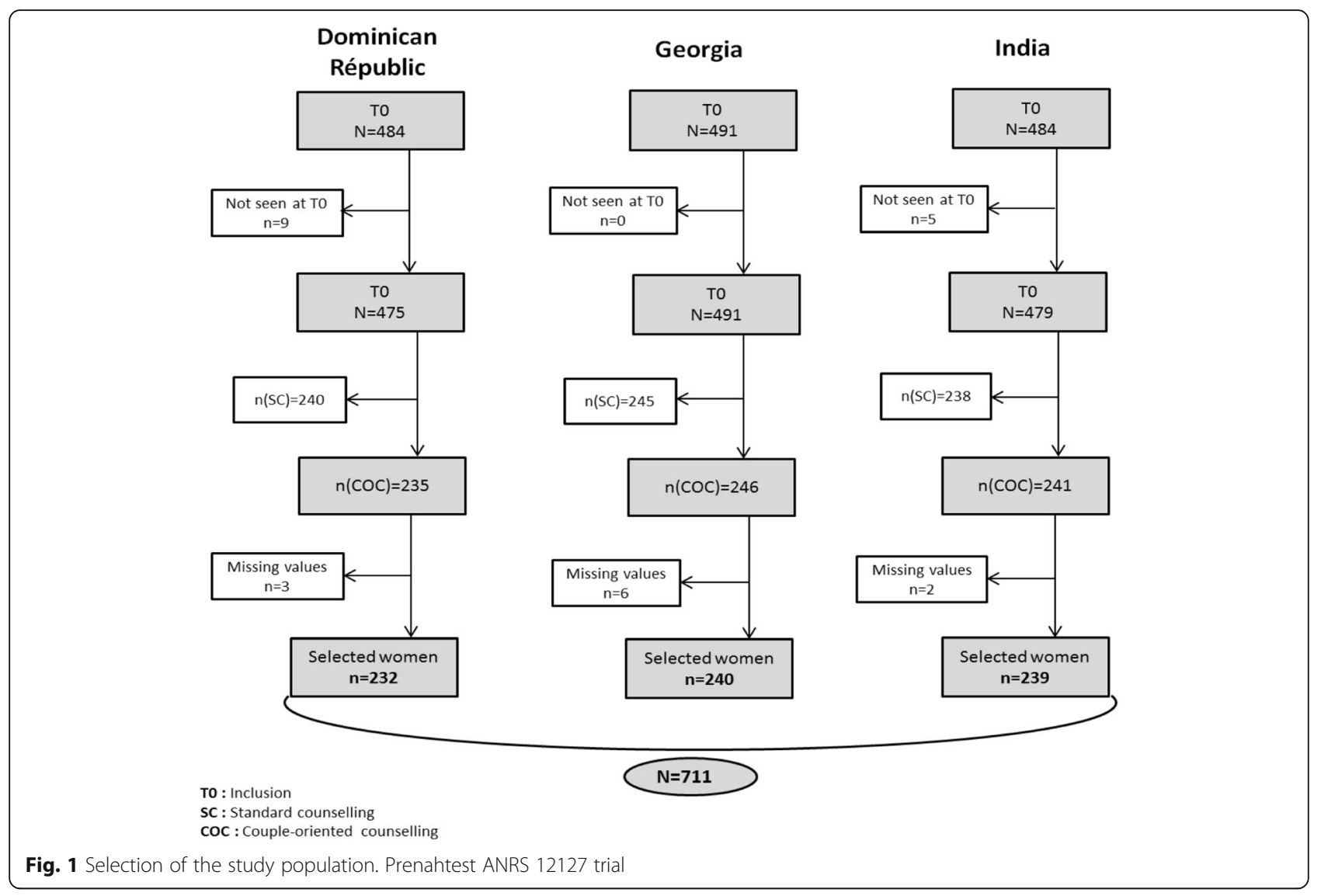

Uptake of couples HIV counseling at the end of the trial Among the 711 women included in this analysis, 131 were seen at T1 only, 507 at T1 and T2, 11 at only T2 and 62 were not seen neither at T1 nor T2. A total of 141 women (19.8\% of all included women) reported receiving couples HIV counseling during the trial, either at T1 (114 women), or at T2 (28 women). The uptake of couples HIV counseling was uneven by country: $9.1 \%$ (21 couples) in the Dominican Republic, 13.8\% (33 couples) in Georgia and $36.8 \%$ (88 couples) in India (Fig. 2).

\section{Individual and couples characteristics associated with the} uptake of couples HIV counseling.

Unadjusted (univariable) analyses are presented in Table 2 and adjusted (multivariable) analyses in Table 3.

In Dominican Republic, the multivariable analysis showed that the uptake of couples HIV counseling was significantly more likely among women who were accompanied by their partner to their first ANC visit $(17.7 \%$ versus $6.1 \%$, adjusted Odds-Ratio $(\mathrm{aOR})=4.10$, $95 \%$ Confidence Interval $(95 \% \mathrm{CI})=[1.51,11.13])$. Couples HIV counseling was also more likely among women who had never used a condom with their partner but had ever discussed it (15.8\%) and among those who had never used a condom and never discussed it with the partner (13.1\%), compared to those who declared ever having used a condom and ever having discussed it with their partner $(5.0 \%$ ) (respectively, $\mathrm{aOR}=6.17$, $95 \% \mathrm{CI}=[1.57,24.20]$ and $\mathrm{aOR}=3.67,95 \% \mathrm{CI}=[1.07$, 12.63]). The uptake of couples HIV counseling was less likely among women who perceived their partner as normally or less supportive of the current pregnancy compared to those who perceived their partner as supportive $(3.5 \%$ versus $12.3 \%$, aOR $=0.26,95 \% \mathrm{CI}=[0.73-$ 0.90]). (Table 2).

In Georgia, the multivariable analysis showed that the uptake of couples HIV counseling was significantly more likely among women with a higher educational level than their partner, compared to the contrary $(27.6 \%$ versus $9.9 \%$, aOR $=3.45,95 \% \mathrm{CI}=[1.56,77])$. The uptake of couples HIV counseling was less likely among women who had never discussed about HIV with their partner, compared to those who had had a discussion about HIV only on general terms ( $7.9 \%$ versus $20.7 \%$, aOR $=0.33$, 95\% CI $=[0.14,0.72])$ (Table 2).

In India, in the multivariable analysis, the uptake of couples HIV counseling was more likely among women who had been accompanied by their partner to their first ANC visit (52.4\% versus $24.6 \%$, OR = $3.37,95 \% \mathrm{CI}=[1.95,5.83]$ ) (Table 2). 
Table 1 Baseline characteristics of women who received couple-oriented post-test HIV counseling. Prenahtest ANRS 12127 trial

\begin{tabular}{|c|c|c|c|c|c|c|}
\hline \multirow{3}{*}{ Individual characteristics } & \multicolumn{2}{|c|}{ Dominican Republic $(N=232)$} & \multicolumn{2}{|c|}{ Georgia $(N=240)$} & \multicolumn{2}{|c|}{ India $(N=239)$} \\
\hline & $n$ & $\%$ & $n$ & $\%$ & $n$ & $\%$ \\
\hline & & & & & & \\
\hline & \multicolumn{2}{|l|}{$21(19-27)$} & \multicolumn{2}{|l|}{$25(22-30)$} & \multicolumn{2}{|c|}{$21(20-23)$} \\
\hline \multicolumn{7}{|l|}{ Age (year) } \\
\hline $16-20$ & 75 & 32.4 & 22 & 9.2 & 56 & 23.4 \\
\hline $20-24$ & 78 & 33.6 & 83 & 34.5 & 141 & 59.1 \\
\hline $25-29$ & 42 & 18.1 & 69 & 28.8 & 34 & 14.2 \\
\hline$>=30$ & 37 & 15.9 & 66 & 27.5 & 8 & 3.3 \\
\hline \multicolumn{7}{|l|}{ Educational level } \\
\hline None, primary and college & 110 & 47.4 & . & . & 113 & 47.2 \\
\hline Secondary & 100 & 43.1 & 70 & 29.2 & 96 & 40.2 \\
\hline Tertiary & 22 & 9.5 & 170 & 70.8 & 30 & 12.6 \\
\hline \multicolumn{7}{|l|}{ Previously tested for HIV } \\
\hline Yes & 134 & 57.8 & 91 & 37.9 & 81 & 33.9 \\
\hline No & 98 & 42.2 & 149 & 62.1 & 158 & 66.1 \\
\hline \multicolumn{7}{|c|}{ Perception of risk of HIV infection from current partner } \\
\hline Yes & 30 & 12.8 & 43 & 17.5 & 7 & 2.9 \\
\hline No & 168 & 71.5 & 157 & 63.8 & 218 & 90.5 \\
\hline Doesn't Know & 37 & 15.7 & 46 & 18.7 & 16 & 6.6 \\
\hline \multicolumn{7}{|l|}{ Partner ever tested for HIV } \\
\hline Yes & 96 & 41.4 & 22 & 9.2 & 21 & 8.8 \\
\hline No & 75 & 32.3 & 156 & 65.0 & 199 & 83.3 \\
\hline Doesn't know & 61 & 26.3 & 62 & 25.8 & 19 & 7.9 \\
\hline \multicolumn{7}{|l|}{ Partner alcohol consumption } \\
\hline Never/Occasionally & 226 & 96.2 & 229 & 93.1 & 225 & 93.4 \\
\hline Frequently & 9 & 3.8 & 17 & 6.9 & 16 & 6.6 \\
\hline \multicolumn{7}{|l|}{ Couple characteristics } \\
\hline \multicolumn{7}{|l|}{ Marital status } \\
\hline Single & 21 & 9.0 & 6 & 2.5 & . & . \\
\hline Free union & 196 & 84.5 & 40 & 16.7 & . & . \\
\hline Married & 15 & 6.5 & 194 & 80.8 & 239 & 100.0 \\
\hline \multicolumn{7}{|l|}{ Educational level difference with partner } \\
\hline Woman more educated than partner & 90 & 38.8 & 58 & 24.2 & 71 & 29.6 \\
\hline Partner more educated than woman $(<=2 \mathrm{y})$ & 63 & 27.1 & 141 & 58.7 & 103 & 43.2 \\
\hline Partner more educated than woman (> 2y) & 48 & 20.7 & 41 & 17.1 & 65 & 27.2 \\
\hline Doesn't know & 31 & 13.4 & . & . & . & . \\
\hline \multicolumn{7}{|l|}{ Age difference with partner } \\
\hline Woman older than partner & 35 & 15.1 & 45 & 18.8 & 5 & 2.1 \\
\hline Partner older than woman (gap <5y) & 83 & 35.8 & 120 & 50.0 & 125 & 52.3 \\
\hline Partner older than woman (gap >5y) & 88 & 37.9 & 75 & 31.2 & 86 & 36.0 \\
\hline Doesn't know & 26 & 11.2 & . & . & 23 & 9.6 \\
\hline
\end{tabular}


Table 1 Baseline characteristics of women who received couple-oriented post-test HIV counseling. Prenahtest ANRS 12127 trial (Continued)

\begin{tabular}{|c|c|c|c|c|c|c|}
\hline & \multicolumn{2}{|c|}{ Dominican Republic $(N=232)$} & \multicolumn{2}{|c|}{ Georgia $(N=240)$} & \multicolumn{2}{|c|}{ India $(N=239)$} \\
\hline & $n$ & $\%$ & $n$ & $\%$ & $n$ & $\%$ \\
\hline \multicolumn{7}{|l|}{ Remunerated activity within couple } \\
\hline Woman or both & 55 & 23.7 & 71 & 29.6 & 49 & 20.5 \\
\hline Partner only & 162 & 69.8 & 123 & 51.3 & 186 & 77.8 \\
\hline None of them & 15 & 6.5 & 46 & 19.1 & 4 & 1.7 \\
\hline \multicolumn{7}{|l|}{ Cohabitation with partner } \\
\hline Not cohabiting with partner & 30 & 12.9 & 15 & 6.3 & 18 & 7.5 \\
\hline Cohabiting with partner only & 178 & 76.7 & 115 & 47.9 & 97 & 40.6 \\
\hline Cohabiting with partner and family-in-law members & 24 & 10.4 & 110 & 45.8 & 124 & 51.9 \\
\hline \multicolumn{7}{|l|}{ Relationship duration (years) } \\
\hline$<1$ & 51 & 22.0 & 77 & 32.1 & 56 & 23.4 \\
\hline $1-5$ & 124 & 53.4 & 113 & 47.1 & 144 & 60.3 \\
\hline$>5$ & 57 & 24.6 & 50 & 20.8 & 39 & 16.3 \\
\hline \multicolumn{7}{|l|}{ Woman accompanied by partner to antenatal care } \\
\hline Yes & 64 & 27.6 & 91 & 37.9 & 105 & 43.9 \\
\hline No & 168 & 72.4 & 149 & 62.1 & 134 & 56.1 \\
\hline \multicolumn{7}{|l|}{ Planning of the current pregnancy with partner } \\
\hline Planned & 98 & 42.2 & 174 & 72.5 & 195 & 81.6 \\
\hline Not planned & 134 & 57.8 & 66 & 27.5 & 44 & 18.4 \\
\hline \multicolumn{7}{|l|}{ Perception of partner support during the pregnancy } \\
\hline Very supportive & 146 & 62.9 & 92 & 38.3 & 164 & 68.6 \\
\hline Supportive/not supportive enough & 86 & 37.1 & 148 & 61.7 & 75 & 31.4 \\
\hline \multicolumn{7}{|c|}{ Emotional or verbal abuse from partner at least once in the last month } \\
\hline Yes & 112 & 48.3 & 62 & 25.8 & 47 & 19.7 \\
\hline No & 120 & 51.7 & 178 & 74.2 & 192 & 80.3 \\
\hline \multicolumn{7}{|c|}{ Physical abuse from partner at least once in the last month } \\
\hline Yes & 24 & 10.3 & 4 & 1.7 & 39 & 16.3 \\
\hline No & 208 & 89.7 & 236 & 98.3 & 200 & 83.7 \\
\hline \multicolumn{7}{|l|}{ Ever discussed about HIV with partner } \\
\hline Never & 89 & 38.4 & 140 & 58.4 & 129 & 54.1 \\
\hline On general terms & 53 & 22.8 & 92 & 38.3 & 83 & 34.7 \\
\hline On personal terms & 90 & 38.8 & 8 & 3.3 & 27 & 11.2 \\
\hline \multicolumn{7}{|l|}{ Condom use with partner and discussion about it } \\
\hline Already used and discussed & 100 & 43.1 & 72 & 30.0 & 64 & 26.8 \\
\hline Already used but never discussed & 33 & 14.2 & 6 & 2.5 & 5 & 2.1 \\
\hline Never used but already discussed & 38 & 16.4 & 37 & 15.4 & 60 & 25.1 \\
\hline Never used and never discussed & 61 & 26.3 & 125 & 52.1 & 110 & 46.0 \\
\hline
\end{tabular}

\section{Discussion}

Our results showed that the uptake of couples HIV counseling within the Prenahtest trial, among women who specifically received an intervention dedicated to supporting a couples approach to HIV counseling and testing, was low in the Dominican Republic and
Georgia (respectively 9.1\% and 13.8\%) and a little higher in India (36.8\%). Further, the uptake of couples HIV counseling was overall lower than what we reported for partner HIV testing [29], highlighting the challenges of providing couples HIV services in antenatal settings. 


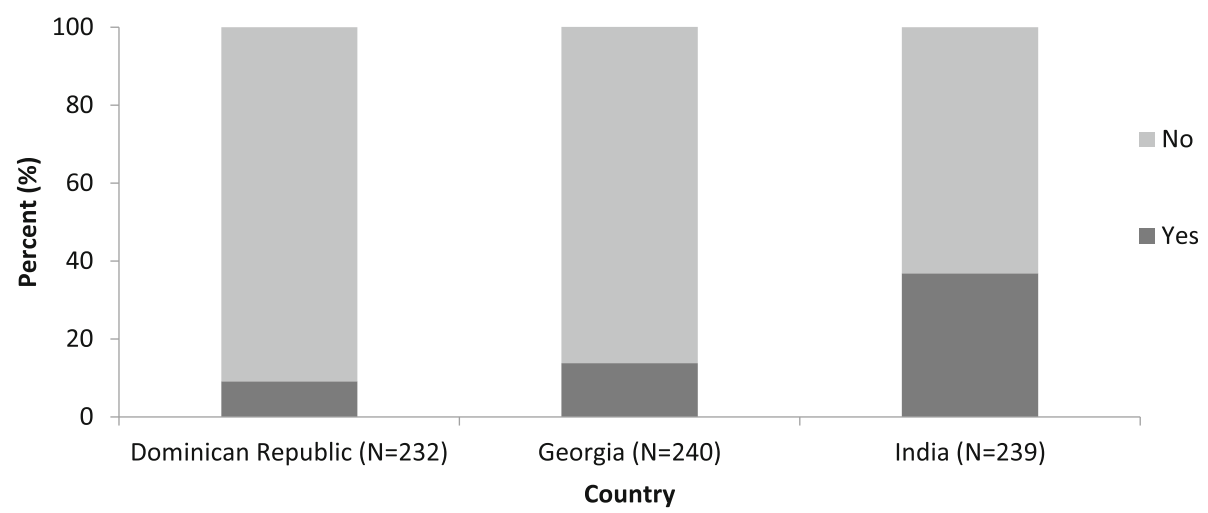

Fig. 2 Uptake of couples HIV counseling among women who received couple-oriented post-test counseling. Prenahtest ANRS 12127 trial

Our analysis also provided insight into the profile of women and their partner who engaged in couples HIV counseling, which varied substantially across study sites. In Georgia, couples in which the woman was more educated than her partner were more likely to receive couples HIV counseling. The role of education level on the acceptability and impact of behavioral interventions has been shown in several low HIV prevalence contexts, including in India [30,31]. More educated woman may have had stronger confidence to initiate discussion about HIV and better negotiation skills within their couple relationship to encourage their partner to receive couples HIV counseling. Previous discussions about HIV within the couple also contributed to a better uptake of couples HIV counseling. Thus, promoting communication within couples and bringing information about HIV to both couple members might contribute to improve couples HIV counseling uptake in the Georgian context.

In India, only one characteristic was associated with the uptake of couples HIV counseling: the fact that the woman was accompanied by the partner to ANC. The presence of men in ANC seems to have triggered some form of "provider-initiated couples HIV counseling", which proved highly effective. These findings are comparable with those recently reported in a pilot project in 15 hospitals in Thailand, with a very high uptake of couples HIV counseling among women accompanied by their partner to ANC [32].

In the Dominican Republic, in addition to women being accompanied to ANC by their partner, women's perception of a strong involvement of their partner in the pregnancy was associated with the uptake of couples HIV counseling. This association was not found in the two others countries or in the literature. Also, couples that had never used a condom were more likely to receive couples HIV counseling than those who had already used condoms and discussed about it. These results may be explained by the fact that couples with little information on HIV might feel less anxious about HIV screening. This hypothesis is supported by the results of a study conducted in Kenya in 2001 that found that men who opted for couples HIV counseling had less knowledge about HIV than those who chose individual HIV counseling [33].

One of the limits of our study may be that we restricted our analysis to women from the intervention group. This choice was made based on methodological reasons, as in Georgia, no women from the SC group had reported receiving couples HIV counseling. The fact that we excluded one of the four study sites may have led to a partial appreciation of Prenahtest results, but this choice was motivated by epidemiological reasons, as Cameroon has a much higher HIV prevalence than the three other sites, with prevalence rates below $1 \%$. Finally, the fact that all data were self-reported by women may have led in part to an information bias regarding partner and couple characteristics.

Overall however, this multi-site analysis allowed investigating couples HIV counseling in three very different socio-demographic contexts, while ensuring a standardized approach in comparing results between sites. Our analysis added to the scarce literature on couples HIV prevention in low-income, low HIV prevalence and nonAfrican cultural settings.

These findings suggest overall that improving the uptake of couples HIV counseling will require substantial structural changes, such as improving women's education level or encouraging an evolution in gender norms to facilitate the presence of men in health services for sexual and reproductive health and to strengthen the ability of women to discuss HIV with their partners. The urgent need for an improved HIV response does not fit well with such longterm behavior change. However, the current changes in the HIV care landscape with the generalization of ART, which will impact on individual health, may sooner impact couple relationships and contribute to higher acceptability and uptake of biomedical and behavioral interventions that address couple concerns. 


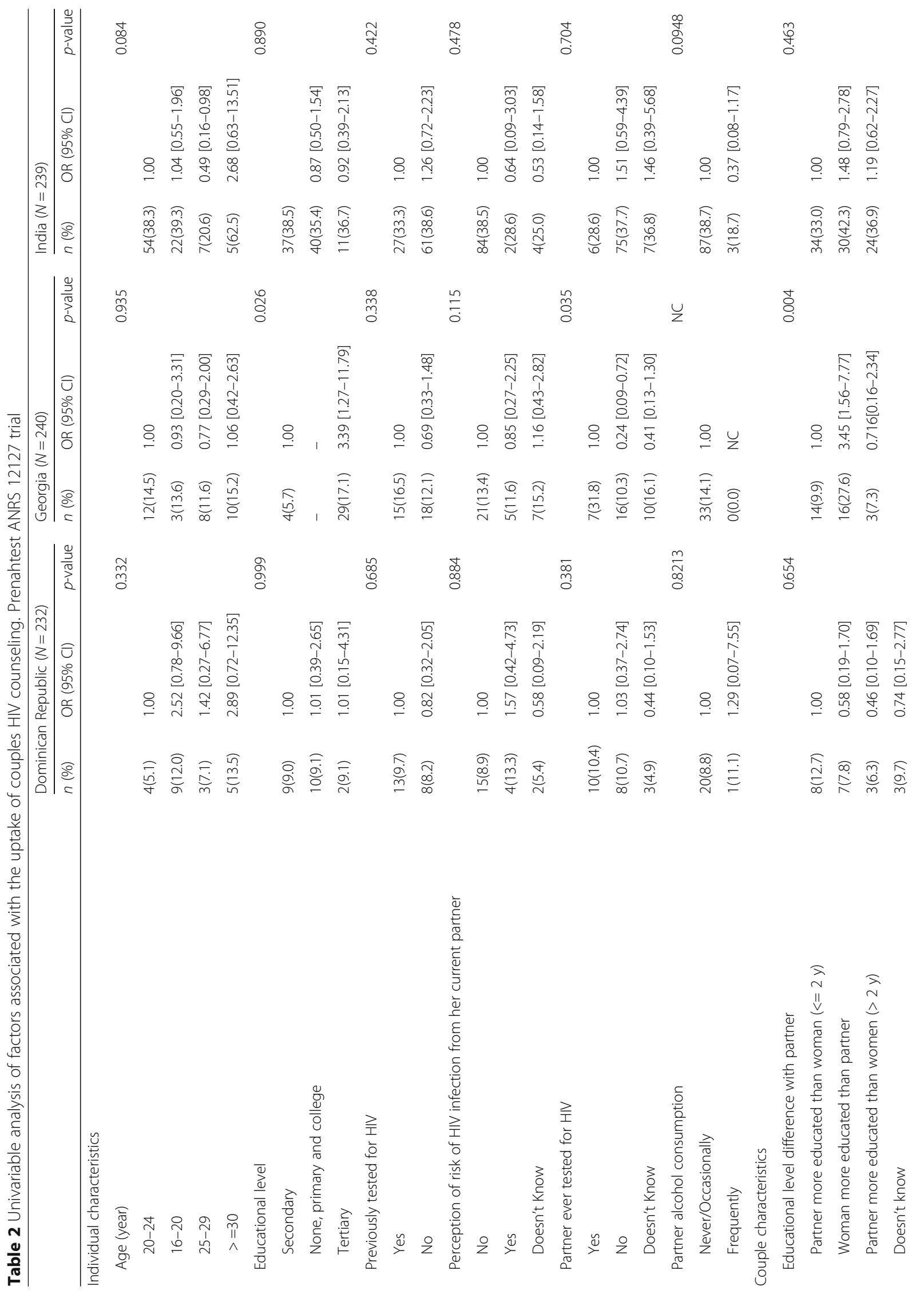




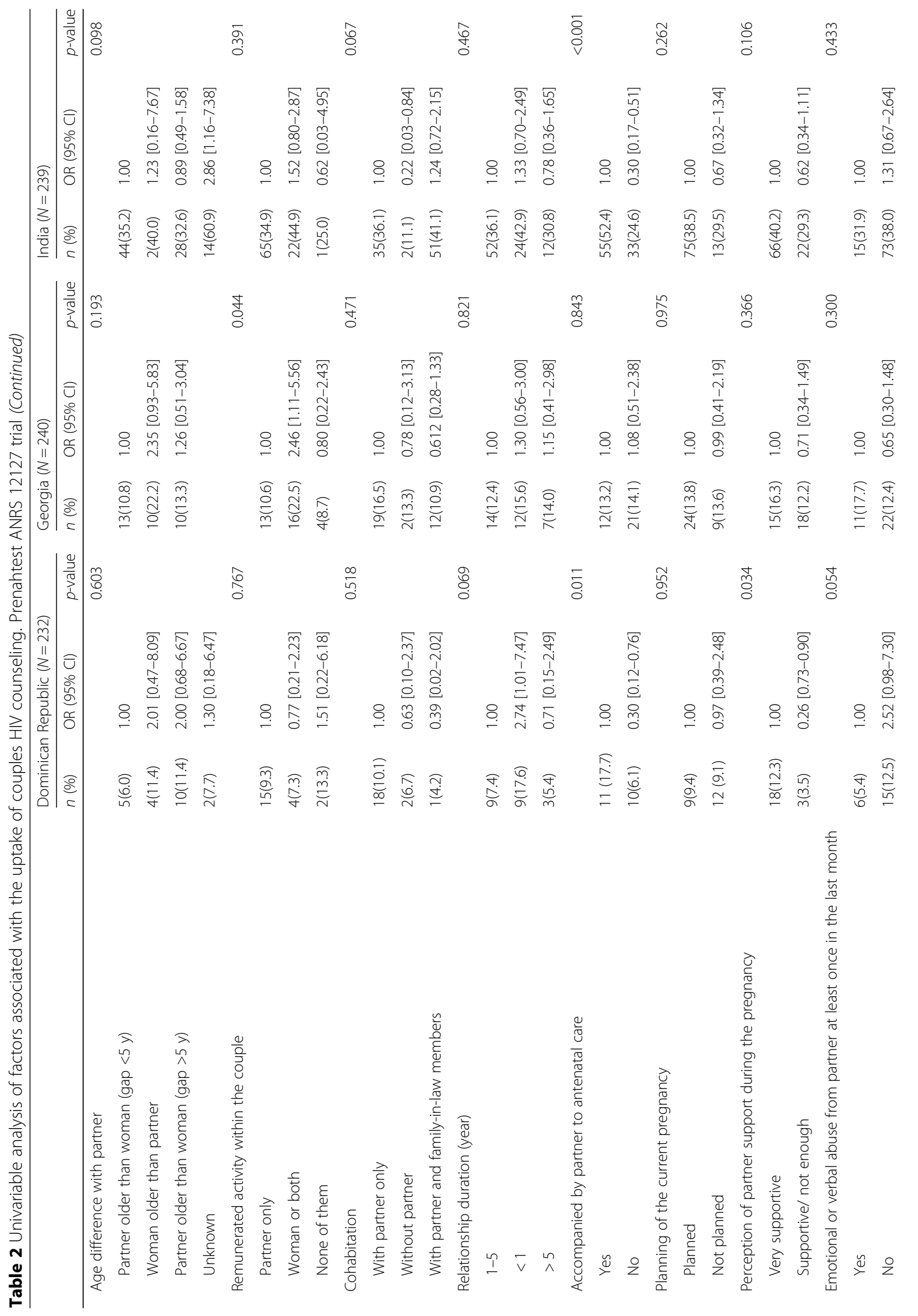




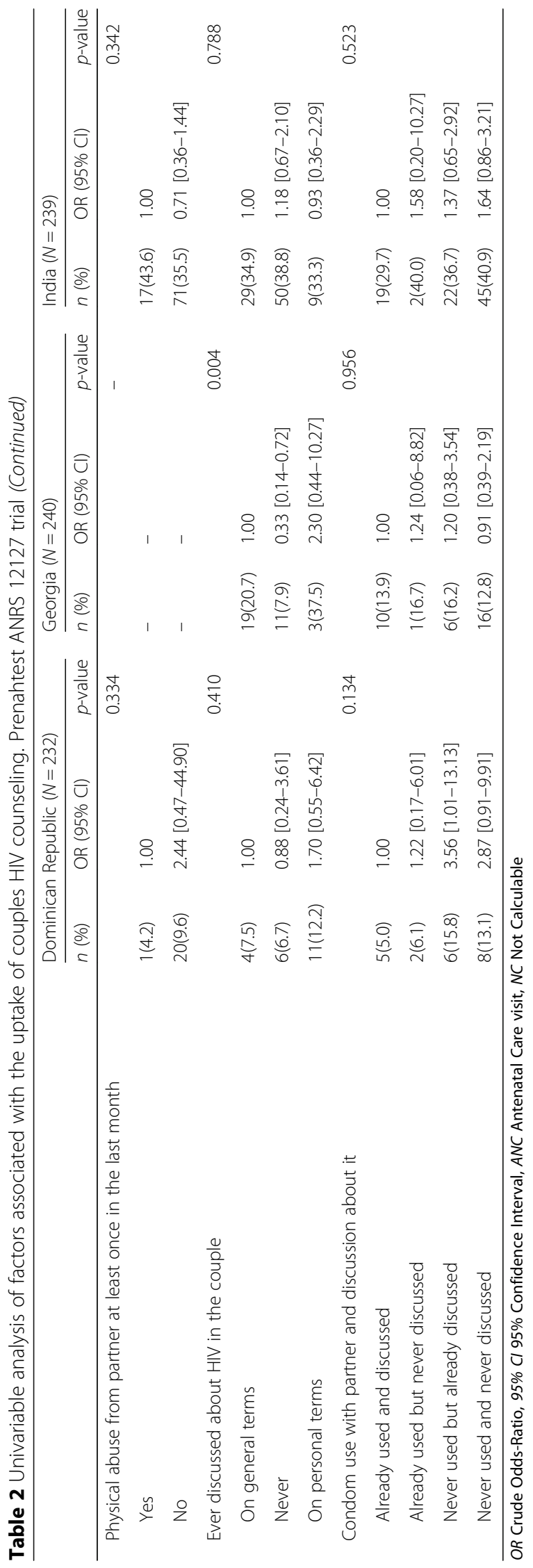




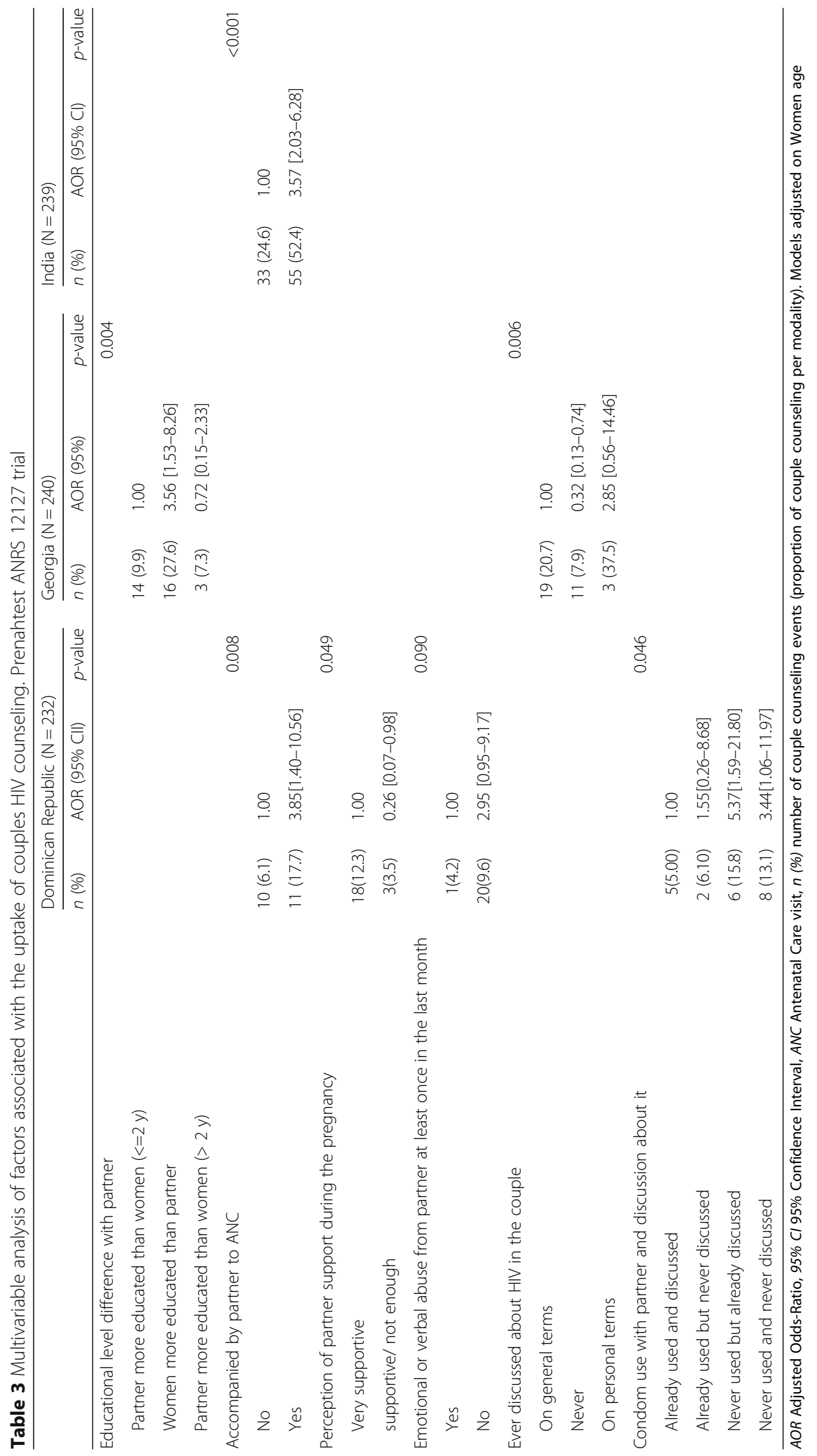




\section{Conclusion}

Although the efficacy of the COC intervention tested within the Prenahtest trial was limited in terms of uptake of couples HIV counseling, we showed previously its value in improving partner HIV testing [29] and short-term communication about HIV within couples [34]. Other couples-centered strategies have been evaluated to increase the uptake of HIV testing and the adoption of HIV prevention strategies within couples. These are essentially community-based interventions such as home-based visits [35-37], and clinic-based interventions such as invitation letters from health care workers to partners [38]. The efficacy of women-delivered HIV self-test in reaching men, who remain underserved by existing services, is about to be evaluated [39]. Combined strategies, tailored to the socio-cultural context, will be critical to improve the uptake of couples HIV counselling and testing and overall interventions for HIV prevention among couples in low to medium HIV prevalence countries.

\section{Abbreviations}

ANC: Antenatal care; ANRS: Agence Nationale de Recherches sur le SIDA et les hépatites virales; AOR: Adjusted odds-ratio; ART: Antiretroviral treatment; Cl: Confidence interval; COC: Couple-Oriented post-test HIV Counselling; OR: Crude Odds-Ratio; PMTCT: Prevention of mother-to-child transmission; PreP: Pre-exposure Prophylaxis; SC: Standard post-test HIV Counselling

\section{Acknowledgements}

The authors thank the site coordinators and the fieldwork teams for their dedication as well as the counselors dedicated to providing women with the best possible service. Special thanks to Brigitte Bazin, Claire Rekacewicz and Laurence Quinty (ANRS), and Catherine Wilfert (EGPAF) for encouraging the study team throughout the trial.

\section{Funding}

This work was supported by the Agence Nationale de Recherches sur le SIDA et les hépatites virales (French National Agency on AIDS Research) (grant ANRS 12127). Complementary funding was provided by the Elizabeth Glaser Pediatric AIDS Foundation (Sub-agreement 354-07). No funding bodies had any role in study design, data collection and analysis, decision to publish, or preparation of the manuscript.

\section{Availability of data and materials}

The datasets supporting the conclusions of this article are stored at Bordeaux Population Health Research Center (Inserm U1219), Bordeaux, France, and may be made available upon request.

\section{Authors' contributions}

TT, MP and JOG defined the research question and methods to respond to this question. TT performed the statistical analysis. T, MP and JOG produced the first article draft. SD, MM, EPT, MB, PT and FD critically revised the manuscript and brought substancial contribution in interpretation and discussion of results. All authors read and approved the final version.

\section{Ethics approval and consent to participate}

The Prenahtest study was approved by Comité de Ética Indepediente, Fundación Dominicana de Infectología (9 April 2007, Dominican Republic), IRB 00006752 of Maternal and Child Care Union (13 November 2008, Georgia), Independent Ethics Committee for Prayas Health Group (27 March 2007, India). Women eligible to study participation were required to provide written informed consent prior enrolment. Participants were assigned identification numbers and all the questionnaires and process forms were labeled with matching numbers to maintain confidentiality.

\section{Consent for publication}

Not applicable. No details, images or videos related to individual participants were obtained.

\section{Competing interests}

The authors declare that they have no competing interests.

\section{Publisher's Note}

Springer Nature remains neutral with regard to jurisdictional claims in published maps and institutional affiliations.

\section{Author details}

${ }^{1}$ INSERM UMR 1219 - Bordeaux Population Health Research Center, Bordeaux, France. ${ }^{2}$ Universite Bordeaux, Institut de Santé Publique, d'Epidémiologie et de Développement (ISPED), 146 rue Leo Saignat, 33076 Bordeaux cedex, France. ${ }^{3}$ Prayas Health Group, Pune, India. ${ }^{4}$ Global Health and Biotechnology Research Center, O\&M Medical School, Santo Domingo, Dominican Republic. ${ }^{5}$ Health Research Union, Tbilisi, Georgia. ' Laboratoire d'Epidémiologie et de Santé Publique, Centre Pasteur du Cameroun, Yaoundé, Cameroon. ${ }^{7}$ Réseau International des Instituts Pasteurs, Paris, France.

Received: 5 October 2016 Accepted: 12 November 2017

Published online: 25 November 2017

References

1. UNAIDS. AIDS by the numbers, AIDS is not over, but it can be; 2016. Available from http://www.unaids.org/sites/default/files/media_asset/AIDS by-the-numbers-2016 en.pdf. Accessed 27 Mar 2017.

2. Eyawo O, de Walque D, Ford N, Gakii G, Lester RT, Mills EJHIV. Status in discordant couples in sub-Saharan Africa: a systematic review and metaanalysis. Lancet Infect Dis. 2010;10(11):770-7.

3. Chemaitelly H, Awad SF, Shelton JD, Abu-Raddad LJ. Sources of HIV incidence among stable couples in sub-Saharan Africa. J Int AIDS Soc. 2014;17:18765

4. Hugonnet S, Mosha F, Todd J, Mugeye K, Klokke A, Ndeki L, et al. Incidence of HIV infection in stable sexual partnerships: a retrospective cohort study of 1802 couples in Mwanza Region, Tanzania. J Acquir Immune Defic Syndr 1999. 2002;30(1):73-80

5. Carpenter LM, Kamali A, Ruberantwari A, Malamba SS, Whitworth JA. Rates of HIV-1 transmission within marriage in rural Uganda in relation to the HIV sero-status of the partners. AIDS. 1999;13(9):1083-9.

6. Malamba SS, Mermin JH, Bunnell R, Mubangizi J, Kalule J, Marum E, et al. Couples at risk: HIV-1 concordance and discordance among sexual partners receiving voluntary counseling and testing in Uganda. J Acquir Immune Defic Syndr. 2005;39(5):576-80.

7. UNDP (2015). Preventing HIV transmission in intimate partner relationships: evidence, strategies and approaches for addressing concentrated HIV epidemics in Asia.Bangkok, UNDP. Available from: http://www.asia-pacific. undp.org/content/dam/rbap/docs/Research\%20\&\%20Publications/hiv_aids/ rbap-hhd-2015-preventing-hiv-transmission-in-intimate-partner-relationships. pdf. Accessed 19 July 2017

8. Newmann S, Sarin P, Kumarasamy N, Amalraj E, Rogers M, Madhivanan P, et al. Marriage, monogamy and HIV: a profile of HIV-infected women in south India. Int J STD AIDS. 2000;11(4):250-3.

9. Cohen MS, Chen YQ, McCauley M, Gamble T, Hosseinipour MC, Kumarasamy $\mathrm{N}$, et al. Prevention of HIV-1 infection with early antiretroviral therapy. N Engl J Med. 2011:365(6):493-505.

10. Baeten JM, Donnell D, Ndase P, Mugo NR, Campbell JD, Wangisi J, et al. Antiretroviral prophylaxis for HIV prevention in heterosexual men and women. N Engl J Med. 2012;367(5):399-410.

11. World Health Organization. Guideline on when to start antiretroviral therapy and on pre-exposure prophylaxis for HIV. Available from: http://apps.who. int/iris/bitstream/10665/186275/1/9789241509565_eng.pdf. Accessed 19 July 2017

12. Allen S, Meinzen-Derr J, Kautzman M, Zulu I, Trask S, Fideli U, et al. Sexual behavior of HIV discordant couples after HIV counseling and testing. AIDS Lond Engl. 2003;17(5):733-40.

13. Syvertsen $\mathrm{J}$, Robertson AM, Rolón ML, Palinkas LA, Martinez G, Rangel MG, et al. Eyes that don't see, heart that doesn't feel: coping with sex work in 
intimate relationships and its implications for HIV/STI prevention. Soc Sci Med 1982. 2013;87:1-8.

14. Allen S, Tice J, Van de Perre P, Serufilira A, Hudes E, Nsengumuremyi F, et al. Effect of serotesting with counselling on condom use and seroconversion among HIV discordant couples in Africa. BMJ. 1992;304(6842):1605-9.

15. McMahon JM, Pouget ER, Tortu S, Volpe EM, Torres L, Rodriguez W, Couplebased HIV. Counseling and testing: a risk reduction intervention for US drug-involved women and their primary male partners. Prev Sci off I Soc Prev Res. 2015;16(2):341-51.

16. El-Bassel N, Wechsberg WM. Couple-based behavioral HIV interventions: placing HIV risk-reduction responsibility and agency on the female and male dyad. Couple Fam Psychol Res Pract. 2012;1 (2):94-105.

17. McMahon JM, Tortu S, Pouget ER, Torres L, Rodriguez W, Hamid R. Effectiveness of couple-based HIV counseling and testing for women substance users and their primary male partners: a randomized trial. Adv Prev Med. 2013;2013:286207.

18. Medley A, Baggaley R, Bachanas P, Cohen M, Shaffer N, Lo Y-R. Maximizing the impact of HIV prevention efforts: interventions for couples. AIDS Care. 2013;25(12):1569-80

19. UNAIDS. The impact of voluntary counselling and testing. A global review of the benefits and challenges. Geneva: UNAIDS; 2001. Available from http://data.unaids.org/Publications/RC-pub02/jc580-vct_en.pdf. Accessed 19 July 2017

20. Kilembe W, Wall KM, Mokgoro M, Mwaanga A, Dissen E, Kamusoko M, et al. Implementation of couples' voluntary HIV counseling and testing services in Durban, South Africa. BMC Public Health. 2015;15:601.

21. Jefferys LF, Nchimbi P, Mbezi P, Sewangi J, Theuring S. Official invitation letters to promote male partner attendance and couple voluntary HIV counselling and testing in antenatal care: an implementation study in Mbeya region, Tanzania. Reprod Health. 2015;12:95.

22. Allen S, Karita E, Chomba E, Roth DL, Telfair J, Zulu I, et al. Promotion of couples' voluntary counselling and testing for HIV through influential networks in two African capital cities. BMC Public Health. 2007;7:349.

23. Wall KM, Kilembe W, Nizam A, Vwalika C, Kautzman M, Chomba E, et al. Promotion of couples' voluntary HIV counselling and testing in Lusaka, Zambia by influence network leaders and agents. BMJ Open. 2012;2(5)

24. Wall KM, Kilembe W, Vwalika B, Haddad LB, Lakhi S, Onwubiko U, et al. Sustained effect of couples' HIV counselling and testing on risk reduction among Zambian HIV serodiscordant couples. Sex Transm Infect. 2017;

25. Karita E, Nsanzimana S, Ndagije F, Wall KM, Mukamuyango J, Mugwaneza P, et al. Implementation and Operational Research: Evolution of Couples' Voluntary Counseling and Testing for HIV in Rwanda: From Research to Public Health Practice. J Acquir Immune Defic Syndr 1999. 2016;73(3):e51-8.

26. World Health Organization. Global update on the health sector responce to HIV, 2014: HIV reporting. Geneva: World Health Organization; 2014. Available from: http://apps.who.int/iris/bitstream/10665/128196/1/WHO_HIV_2014.15_ eng.pdf. Accessed 19 July 2017.

27. Jiwatram-Negrón T, El-Bassel N. Systematic review of couple-based HIV intervention and prevention studies: advantages, gaps, and future directions. AIDS Behav. 2014;18(10):1864-87.

28. UNAIDS. UNAIDS | countries, 2014 [internet]. [cited January 12,2017]. Available from: http://www.unaids.org/en/regionscountries/countries. 2015.

29. Orne-Gliemann J, Balestre E, Tchendjou P, Miric M, Darak S, Butsashvili M, et al. Increasing HIV testing among male partners. AIDS. 2013;27(7):1167-77.

30. Gupta D, Lhewa D, Viswanath R, Jacob SM, Parameshwari S, Radhakrishnan $R$, et al. Effectiveness of antenatal group HIV voluntary counseling and testing services in rural India. AIDS Educ Prev Off Publ Int Soc AIDS Educ. 2007;19(3):187-97.

31. Das A, Babu GR, Ghosh P, Mahapatra T, Malmgren R, Detels R. Epidemiologic correlates of willingness to be tested for HIV and prior testing among married men in India. Int J STD AIDS. 2013;24(12):957-68,

32. Lolekha R, Kullerk N, Wolfe Ml, Klumthanom K, Singhagowin T, Pattanasin S, et al. Assessment of a couples HIV counseling and testing program for pregnant women and their partners in antenatal care (ANC) in 7 provinces, Thailand. BMC Int Health Hum Rights. 2014;14:39.

33. Katz DA, Kiarie JN, John-Stewart GC, Richardson BA, John FN, Farquhar C Male perspectives on incorporating men into antenatal HIV counseling and testing. PLoS One. 2009;4(11):e7602.

34. Plazy M, Orne-Gliemann J, Balestre E, Miric M, Darak S, Butsashvili M, et al. Enhanced prenatal HIV couple oriented counselling session and couple communication about HIV (ANRS 12127 Prenahtest trial). Rev Dépidémiologie Santé Publique. 2013;61(4):319-27.

35. Doherty T, Tabana H, Jackson D, Naik R, Zembe W, Lombard C, et al. Effect of home based HIV counselling and testing intervention in rural South Africa: cluster randomised trial. BMJ. 2013;f3481:346.

36. Fylkesnes K, Sandøy IF, Jürgensen M, Chipimo PJ, Mwangala S, Michelo C Strong effects of home-based voluntary HIV counselling and testing on acceptance and equity: a cluster randomised trial in Zambia. Soc Sci Med 1982. 2013;86:9-16.

37. Osoti AO, John-Stewart G, Kiarie J, Richardson B, Kinuthia J, Krakowiak D, et al. Home visits during pregnancy enhance male partner HIV counselling and testing in Kenya: a randomized clinical trial. AIDS. 2014;28(1):95-103.

38. Mohlala BKF, Boily M-C, Gregson S. The forgotten half of the equation: randomized controlled trial of a male invitation to attend couple voluntary counselling and testing. AIDS. 2011;25(12):1535-41.

39. Choko AT, Kumwenda MK, Johnson CC, Sakala DW, Chikalipo MC, Fielding $\mathrm{K}$, et al. Acceptability of woman-delivered HIV self-testing to the male partner, and additional interventions: a qualitative study of antenatal care participants in Malawi. J Int AIDS Soc. 2017;20(1):1-10.

\section{Submit your next manuscript to BioMed Central and we will help you at every step:}

- We accept pre-submission inquiries

- Our selector tool helps you to find the most relevant journal

- We provide round the clock customer support

- Convenient online submission

- Thorough peer review

- Inclusion in PubMed and all major indexing services

- Maximum visibility for your research

Submit your manuscript at www.biomedcentral.com/submit

) Biomed Central 